\title{
Marking a decade
}

\author{
This month marks 10 years since the first issue of Nature Climate Change. In this issue, we reflect on developments \\ in research areas over those years and celebrate some memorable papers published in our pages.
}

T en years ago this month, Nature Climate Change was launched. Much has changed in those 10 years there has been ongoing warming around the globe: the year of our fifth anniversary, 2016, set the record for warmest on record, with 2020 now joining it in a tie; additionally, there have been more frequent extremes, global weirding has become more pronounced and the post-Copenhagen disappointment shifted to Paris elation followed by deflation as the USA left, fracturing the union. This nationalism, also seen in other locations around the world, threatened international collaboration but also strengthened resolve among other nations to keep the momentum. Understanding of climate change has continued to deepen, and the IPCC released three special reports, promoting interdisciplinarity by having such reports span the well-established Working Groups; also, there has been increased public engagement, in particular from the youth movement, sparked by Greta Thunberg; then, in 2020, the world many of us knew was turned upside down in response to the pandemic.

At the time of launch, Nature Climate Change was the first thematic, rather than subject, journal in the Nature stable. The inaugural Editorial (Nat. Clim. Change 1, 1; 2011), in April 2011, laid out our aspirations to "draw overdue attention to the value of interdisciplinary collaborations, so that they increasingly attract more in the way of human and financial resources. Bright minds from every discipline of research will be needed to fully comprehend and tackle the problem of climate change." We still work towards this aspiration, but take pride in the diversity of subjects published.

The journal is what it is thanks to our authors, reviewers and readers. The community has embraced the journal, and we are humbled to be part of it. Our pages have been filled with top-quality research, enhanced through the peer-review process; none of which would be possible without the help of over 6,150 reviewers. We have received submissions from 130 countries, as climate change is a global issue that needs knowledge sharing across locations as well as disciplines.

For our fifth anniversary (https://go. nature.com/3tOttz8), we selected five papers

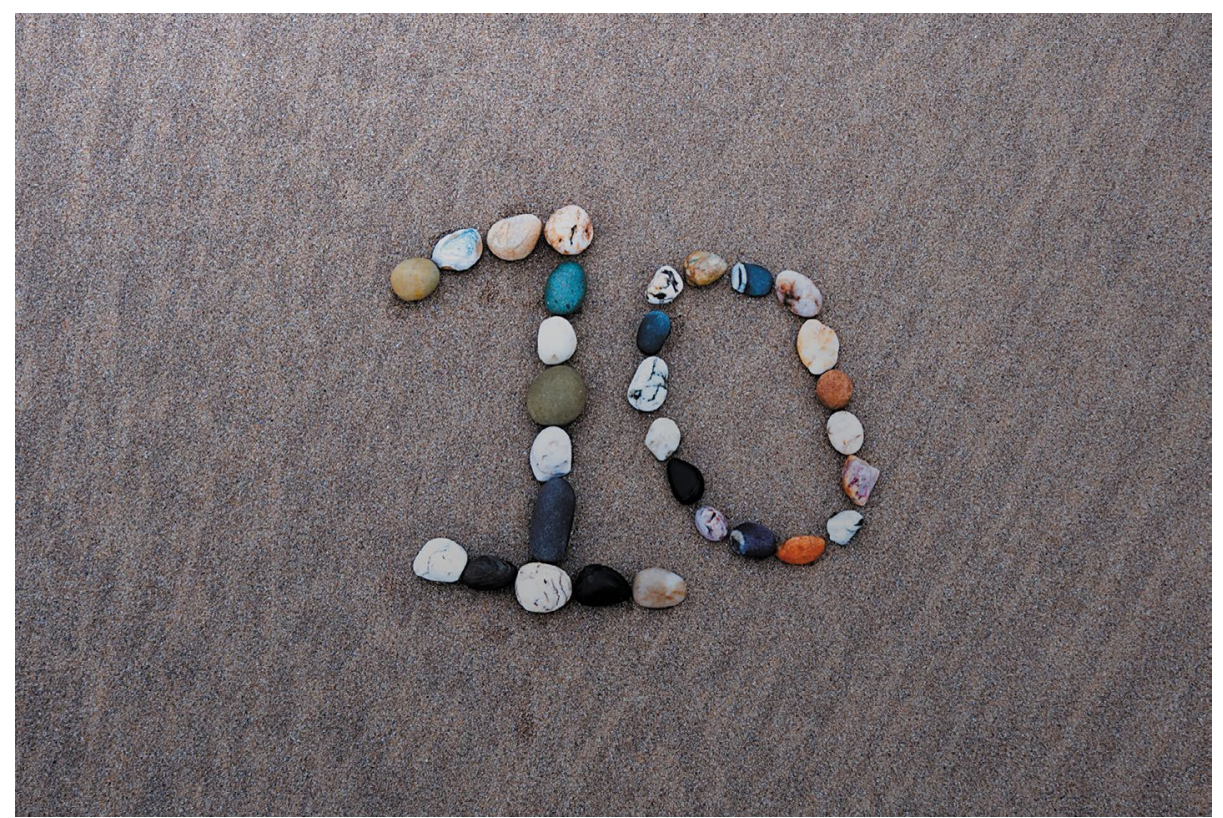

Credit: Phansit Srisaeng / EyeEm/EyeEm/Getty

to revisit in our News \& Views section to see the influence they had on research in the years following their publication, as well as a Feature (Nat. Clim. Change 6, 335-338; 2016) on changes in the research landscape for that time. To celebrate the tenth anniversary, we have again reflected on how our understanding of climate change and its impacts has developed in the Viewpoint in this issue. The piece was written by ten invited experts, spanning a range of research communities, to discuss major milestones, but also allowed them the opportunity to signpost what they see as the next frontiers. Thinking back to the aspiration from the launch Editorial, the sentiment for all disciplines to engage is echoed by some of these contributors.

Our editorial team has changed over the years, and we took this anniversary as an opportunity to reconnect with some of our former colleagues. Past and present editors chose a memorable paper they had shepherded to publication, and share these experiences in a Feature in this issue. The papers selected span the decade of the journal and highlight the diverse content that we have published. The reasons as to why a paper was memorable vary, from the excitement of new approaches, to engagement with the community; we hope you enjoy this small insight into our thinking and what goes on behind the scenes as editors.

In our fifth anniversary Editorial (Nat. Clim. Change 6, 331; 2016), we wrote that the occasion brought into "sharp focus that there is no time like the present to get serious about climate change. A lot has happened in five years, but a significant acceleration of efforts will be needed in the next five if the world is going to meet the challenges posed by climate change." While we take the time to celebrate our milestone, we won't rest on our laurels. Nature Climate Change will continue working to support and bring academics, stakeholders and policymakers together to advance mitigation and adaptation to climate change. Progress has been made, but there is still a long road ahead to ensure a sustainable future for all.

Published online: 1 April 2021

https://doi.org/10.1038/s41558-021-01029-2 